Division of General Medicine, Beth Israel Deaconess Medical Center, Boston, MA, USA

2 Harvard Medical School, Boston, MA, USA

3 Department of Women's and Children's Health, Uppsala University, Uppsala, Sweden

Correspondence to: L Salmi Isalmi@bidmc.harvard.edu

Cite this as: BMJ 2021;372:n426 http://dx.doi.org/10.1136/bmj.n426 Published: 18 February 2021

\section{US policy requires immediate release of records to patients}

\author{
Patients and clinicians should embrace the opportunities \\ Liz Salmi, ${ }^{1}$ Charlotte Blease, ${ }^{1,2}$ Maria Hägglund, ${ }^{3}$ Jan Walker, ${ }^{1,2}$ Catherine M DesRoches ${ }^{1,2}$
}

On 5 April a new federal rule will require US

healthcare providers to give patients access to all the health information in their electronic medical records without charge. ${ }^{1}$ This new information sharing rule from the 21st Century Cures Act of $2016^{2}$ mandates rapid, full access to test results, medication lists, referral information, and clinical notes in electronic formats, on request.

The US is not alone in providing patients with full online access to their electronic health records. In Sweden, patients gained access to their records between 2012 and 2018. ${ }^{3}$ Estonian citizens have had full access since 2005.4 The sharing of personal health information isn't without precedent in the US: around 55 million people already have access to their online clinical notes, ${ }^{5}$ and many more have access to laboratory results and other parts of their records. But for some US clinicians, the new rule may feel like a shock. ${ }^{6}$

To patient groups, however, it is the culmination of 25 years of advocacy and relationship building with clinicians, researchers, and policy makers. Back in 1996, the Health Insurance Portability and Accountability Act gave patients the legal right to request and receive copies of their records, ${ }^{7}$ but this takes time, effort, and money. ${ }^{8}$ The new information sharing rule will enable anyone receiving healthcare in the US free, timely access to both ambulatory and inpatient care records through secure online portals. The new legislation also stipulates that people should be able to download their data to third party digital applications (apps) and aggregate all their health records into their digital platform of choice by October 2022, allowing people to share health information with anyone involved in their care.

Studies show that patients who read what is written about them by clinicians feel more involved in and knowledgeable about their care, feel better prepared for visits, and report being more likely to follow their clinicians' advice. ${ }^{9}$ These results are consistent across ethnic groups, gender, socioeconomic status, and education, and the same benefits accrue to family caregivers. ${ }^{10}$

As with all innovations, some concerns have been raised. The rule requires all test results-including imaging and pathology reports-to be released without delay. Some people may therefore learn of a cancer diagnosis, for example, from an online health record alert rather than during a conversation with a clinician. In a study from Sweden, however, many cancer patients who regularly accessed their personal health information reported that immediate access to test results actually reduced what patients term "scanxiety." "11 As the US moves to a more transparent health record ecosystem, there will be an opportunity to elicit patients' views and experiences of the benefits and risks of receiving test results in real time. In the future, it should be possible to ensure patients have a choice over how and when they receive health information.

Patients have much to gain from the new rule on information sharing. Around $80 \%$ of internet users search for health information online ${ }^{12}$; combining these searches with personal health information from the medical record is likely to result in more accurate, relevant, and useful information. On the other hand, legitimate concerns include a greater infringement of online vulnerability associated with search engines collating and selling medical data that people now provide freely without fully comprehending the long term consequences. ${ }^{1314}$

A further concern is that the new US rule allows clinicians to block information. A "preventing harm" exception allows clinicians to hide information from patient view if they believe the patient may harm themselves or others as a result of reading their personal health information. Recognising that this discretionary right may be misused, the US Department of Health and Human Services has established an online reporting system for "information blocking" - that is, hiding information from patients.

Finally, the new rule still does not change who owns health records outright. Records remain the property of hospitals or doctors in half of all US states. Laws in the remaining states view records as having shared ownership with patients.

US healthcare organisations may choose to comply with the rule in a way that helps ensure patients know about their enhanced right to access and use their health information for empowerment and engagement, or they may simply keep quiet about it and hope patients don't notice their new rights. Choosing to keep quiet would be a mistake. Full sharing and transparency of personal health information should strengthen patient-clinician communication, raise health literacy, promote self-management, enhance teamwork, and increase trust. Patients' voices must now be put at the centre of discussions and debates about information and data sharing in healthcare to ensure that all reap the benefits of the digital age.

Competing interests: We have read and understood BMJ policy on declaration of interests and declare the following interests: $\mathrm{LS}, \mathrm{CB}$, and CMB receive financial support in the form of grants from the Cambia Health Foundation, the John A Hartford Foundation, the New York State Health Foundation, the Department of Health and Human Services Office of the National Coordinator for Health Information Technology, and the Agency for Health Care Quality and Research. LS serves on the BMJ patient advisory panel and on the volunteer board of directors for the National Brain Tumor Society. MH is funded by several public 
research grants from NordForsk, Forte (the Swedish research council for health, working life and welfare), and AFA.

Provenance and peer review: Commissioned; not externally peer reviewed.

1 Office of the National Coordinator for Health Information Technology. ONC's Cures Act final rule. 2020. https://www.healthit.gov/curesrule

2 Lengyel-Gomez B. 21st Century Cures Act-a summary. 2017. https://www.himss.org/resources/21st-century-cures-act-summary

3 Hägglund M, DesRoches C, Petersen C, Scandurra I. Patients' access to health records. BMJ 2019;367:15725. doi: 10.1136/bmj.l5725 pmid: 31578180

4 Nøhr C, Parv L, Kink P, etal. Nationwide citizen access to their health data: analysing and comparing experiences in Denmark, Estonia and Australia. BMC Health Serv Res 2017;17:534. doi: 10.1186/s12913-017-2482-y. pmid: 28784173

5 OpenNotes. New survey data reveals 54 million people are able to access clinicians' visit notes online. 2020. https://www.opennotes.org/news/new-survey-data-reveals-54-million-people-areable-to-access-clinicians-visit-notes-online/

6 Mulcahy N. Patients can read your clinical notes starting Nov 2. Medscape 2020 Oct 21.https://www.medscape.com/viewarticle/939499

7 US Department of Health and Human Services. Your rights under HIPAA. 202.1 https://www.hhs.gov/hipaa/for-individuals/guidance-materials-for-consumers/index.html

8 Lye CT, Forman HP, Gao R, etal. Assessment of US hospital compliance with regulations for patients' requests for medical records. JAMA Netw Open 2018;1:e183014. doi: 10.1001/jamanetworkopen.2018.3014 pmid: 30646219

9 Walker J, Leveille S, Bell S, etal. OpenNotes after 7 years: patient experiences with ongoing access to their clinicians' outpatient visit notes. J Med Internet Res 2019;21:e13876. doi: 10.2196/13876 pmid: 31066717

10 Chimowitz H, Gerard M, Fossa A, Bourgeois F, Bell SK. Empowering informal caregivers with health information: OpenNotes as a safety strategy. Jt Comm J Qual Patient Saf2018:44:130-6. doi: 10.1016/j.jcjq.2017.09.004 pmid: 29499809

11 Rexhepi H, Åhlfeldt RM, Cajander Å, Huvila I. Cancer patients' attitudes and experiences of online access to their electronic medical records: A qualitative study. Health Informatics /2018;24:115-24. doi: $10.1177 / 1460458216658778$ pmid: 27440056

12 Pew Research Center. Internet health resources. 2003. https://www. pewresearch.org/internet/2003/07/16/internet-health-resources/

13 Naughton J. "The goal is to automate us": welcome to the age of surveillance capitalism. Guardian 2019 Jan 20. https://www.theguardian.com/technology/2019/jan/20/shoshana-zuboff-age-ofsurveillance-capitalism-google-facebook

14 Ross C. Google partners with major U.S. health system, gaining access to vast patient data in the process. STAT2019 Nov 11. https://www.statnews.com/2019/11/11/google-partners-withmajor-u-s-health-system-gaining-access-to-vast-patient-data-in-the-process/ 